\title{
CONFLICT AND DEMOCRACY EDUCATION IN PALESTINE
}

\author{
MAHER Z. HASHWEH
}

\begin{abstract}
This paper describes the conflict situations that teachers and students faced when a new problem- and case-based approach to democracy education was used in Palestine. The data for the study were six documentary cases written by teachers who participated in the three-year project, supplemented by the observations and interpretations of the author as a participant observer. The study describes how dedicated and tactful teachers generally succeeded to teach democracy in a largely undemocratic context, and shows that teaching democracy in the manner described perturbed the system, and students and teachers were faced with internal and external conflict situations. These conflict situations sometimes facilitated radical change in the knowledge, beliefs, and behavior of teachers and students. The study underscores the importance of internal cognitive and emotional conflict, in addition to external conflict, in learning, as well as draws attention to the dialectical relation between teachers' efforts to introduce educational change and their own change and professional development.
\end{abstract}

\section{Introduction}

\section{$\mathcal{D}$}

emocracy can be viewed as an important means for the peaceful resolution or management of conflict in a society. It is also a means, for individuals and groups, to influence decision making, that is, to affect change in reality through the use of dialogue and rational debate in order to persuade others and to defend positions, as well as through political participation and activism. Democracy education, to be authentic, has to use these processes of democracy as processes of teaching and learning. However, whereas democracy advocates have largely stressed the role of democracy in the resolution of already-existing conflicts, this article shows that teaching and learning about democracy in Palestine, within a case-based approach that encourages problem-solving, critical thinking, and active participation, emphasizes the creation of conflict, in an already conflict-laden area. The role of those involved in democracy education, students and teachers alike, becomes to face these external and internal conflicts. In some important cases, the protagonists undergo radical change in attempting to resolve these conflicts. The main aim of the present paper is to describe how courageous, dedicated, and tactful teachers can surmount the obstacles to teaching democracy in a generally 
undemocratic context, and to show how teachers who were involved in a democracy education project in Palestine, as well as their students, faced conflict situations that sometimes facilitated radical change in their knowledge, beliefs, or behavior. The paper also aims to underscore the importance of internal cognitive and emotional conflict, in addition to external conflict, in learning, as well as to draw attention to the dialectical relation between teachers' efforts to introduce educational change and their own change and professional development.

The study was based on the assumption that democracy can be taught in the basically undemocratic context of developing countries, and more specifically the Arab States. The situation in Palestine is even the more exceptional one of teaching democracy in a stateless and colonized society. To what degree is this assumption justified? There is a long debate in the educational literature about the causal relationships between educational and societal change. Many, if not most educators, have argued that social change leads educational change, and that education, and schools in particular, play an essentially conservative role of maintaining the status quo and recreating the socio-economic structure in societies. Arab educators (Watfah, 1996, for example) have seen educational institutions, in Durkheim's (1956) perspective, as microcosms of the larger society that produced them, and consequently, they carry society's characteristics and act as tools to sustain that social order. Bowles and Gintis' (1976) seminal study showed how schools in America served to reproduce the economic and social capitalist structure. Watfah (1996) reviewed other French studies in the same strand. That schools play a conservative role in maintaining the status quo is largely accepted now. Accepting this position leads to a pessimistic view about the role of education in inducing change, and to a skeptical position about attempts to teach democracy in undemocratic societies.

Most of the writings about education and child-raring practices in the Arab States can be classified in this strand since they analyzed Arab culture and society to identify its undemocratic 'character' and revealed how this culture affects schooling on the one hand, and how schooling, on the other hand, helps maintain the present culture and society. The leading intellectuals who have criticized Arab culture, home-rearing practices, and schools as barriers to democracy have been Sharabi $(1975,1987)$ and Barakat (1984). Sharabi, for example, pointed out to the patriarchal structure of Arab society, and identified child-rearing and schooling practices that reflect and maintain this society. Barakat identified many traditional values that are in dissonance with democratic values, attitudes and habits of mind. More recently, Watfa $(1996,1999)$ has shown how the authoritarian culture is reflected in, and maintained by, the family and the school relations and practices. Watfa (1999), additionally, reviewed a diverse and rich literature in the Arab States that addresses these issues. Watfa concluded that authoritarianism is closely 
related to the patriarchal structure of Arab societies, that Arab culture emphasizes obedience of the young to the old, that schools train students to become obedient and submissive by embodying these values in student-teacher relations. Al-Naqib (1993) agrees that the role of schools is to develop blind obedience in students and, consequently, to facilitate their acceptance of prevalent societal values and ideology. Other educators have gone further to empirically study the effects of patriarchal relationships on student learning outcomes, for example, on the scientific attitudes of school students (Heidar, 1996).

However, other educators have pointed to the liberating and progressive role of education. There is an important aspect of education that addresses the mind, and that aims to develop intellectual abilities even in a predominantly conservative education context. This, sometimes unintended, by-product of education leads to the development of critical individuals who can reflect on the status quo and work for change. The role of education in promoting social mobility, economic and political development, and modernity in the Developing World in general is known (e.g., Fagerlind \& Saha, 1989). Bahlool (1997), in one of the very few books that addressed education and democracy in the Arab States, took this more optimistic position, and argued that 'every change in society or the political system presupposes change at the individual level' (p.82). He opposed revolutionary or radical instantaneous changes because some members of the new élite will be prone 'to the same shortcomings that were present in the society that produced the élite and in the social culture which the élite is trying to overcome' (pp.82-83). The alternative, according to Bahlool, is in education: "positively affecting any individual in the society is like lighting a candle ... [because] the individual is the staring point just as he is the end point' (p.83).

It is unnecessary to accept either of the two positions in this dualism concerning the relations between social and educational change in order to teach about democracy in predominantly undemocratic contexts. Indeed, it is un-useful to ask the question at this level of generality. The relations are far more complex. For example, most studies assume the existence of one Arab culture. Knowing that there is one dominant culture and many sub-cultures in most societies, the question becomes: which culture is the educational system reflecting and maintaining? In Jordan, for example, can we neglect the differences between a rich private school in West Amman and another rural one in the Jordan Valley? Can we speak, also, about one culture in Palestine, Yemen and Morocco? Can we also reliably assert that the Arab culture is predominantly patriarchal, and take this as our starting point in the study of education and society in the Arab world? Heidar's (1996) aforementioned study revealed that students in this 'patriarchal' society nevertheless believed that there was no intellectual authoritarianism, that is, they could express their differences of opinions with their parents and elders. Hence, 
there were no clear relations between some of the proposed components of patriarchal relations. Additionally, this dualism assumes that powerful forces in the society completely control schooling practices and other means of enculturation, which is not completely true. Schools can be considered as sites for struggles between different groups in society, representing different interests and ideologies. Finally, the individual in these studies is portrayed as a passive receiver of culture and not as an active and selective constructor of his or her knowledge, a learner who is autonomous and who learns in collaboration with others and through acting on the world, that is an individual who acts and interacts in society and not merely an end-receiver of knowledge and values. In light of these considerations, and in light of the world interest in democracy, and the prodemocracy official discourse in many Arab States, educators and teachers have a significant margin of freedom to experiment with teaching democracy in these States. In my opinion, this debate about the causal effects between societal and educational change will not be resolved at the academic level, but rather will be determined by the results of struggles at the concrete level of practice in schools and other institutes of learning, and it is in this spirit that the study was undertaken.

\section{The Democracy Education Project}

The Democracy Education Project was a three-year project that started in September 1998. During the first year of the Project nine high school teachers from private, public, and UNRWA (United Nations Relief and Welfare Agency) schools in the Ramallah area of the West Bank participated in a year-long workshop that met on a weekly basis. During the first semester of the academic year, the teachers were exposed to the philosophy, theoretical bases, and teaching methods of a case-based approach to democracy education. They collaborated, under the leadership of a university-based researcher, in designing a case-based unit. During the second semester they taught the unit in their respective ninth grade classrooms, and continued to meet on a weekly basis to reflect on the teaching of the preceding week, and to plan for the teaching of the forthcoming week.

The teaching unit presented a case about punishment of students in schools, and used it as an anchor for collaborative student learning about various elements of democracy, such as citizenship, the rule of law, the separation of powers, the legislative process, accountability, and basic rights. The teachers agreed upon a set of design criteria to guide the development and teaching of the case. Among these were the necessity of building the case using local events or issues, the use of a problem-based approach, the need for the case to provide a base for creating a 
community of learners, and the requirement that students explicitly plan their investigations before conducting any research. In teaching the unit, students started working as one group to identify problems and questions raised by the case. Consequently, the students worked in small groups to answer questions related to certain elements of democracy, such as the rule of law, or citizenship. Using the jigsaw method, (a method that allows regrouping of students so that each of the students in the new group is an 'expert' on a subtopic, but knows very little on other subtopics), the students were finally re-arranged in new groups to propose solutions to the original problems raised by the case. The teaching of the case lasted for about 16 class periods - a detailed description of this phase of the Project is found in Hashweh \& Njoum (2001).

In the second year of the Project the teachers collaborated in designing five more case-based teaching units. During the first semester of the third year each of six teachers taught one case-based unit in one of the grades nine to 11. During the second semester each of the teachers wrote a documentary case to describe and analyze some aspects of her or his experience in teaching the case-based unit. The teachers continued to meet on a weekly basis throughout the two academic years to reflect and deliberate on their work - the teaching cases and the documentary cases are included in Hashweh (in press).

The six teachers who participated in the three-year Project held Bachelors Degrees (two held Masters Degrees), had teaching experiences ranging from five to 14 years, and their ages ranged from 27 to 38 years. They were teachers of Arabic, English, Social Studies, Mathematics or Physics at grades ranging between seven and 12. The teachers taught in coeducational schools, except in one case where the school was a girls' school. Whereas in the kind of quantitative work used in this study the aim is not to test generalizations, and hence, there is usually no effort to choose representative samples of a certain population, I was conscious of the need to choose schools that are not unique in the Palestinian context as well. The inclusive private schools and the UNRWA school that were selected had students representing the different religious and socioeconomic diversity found in Ramallah. Additionally, there is no reason to believe that there is a local particularity to Ramallah, in the sense that its teachers and students would be different from those in other areas of the West Bank.

The main source for data for this paper came from the six teacher-written documentary cases. I also used my notes and experience as a participant observer in the Project to supplement the accounts portrayed in the teachers' cases. I chose accounts that portray conflict situations faced by students and teachers, that describe how they confronted these situations, and that depict the results of these confrontations. I start by describing the emotional conflict described by teachers participating in the Project. I then describe conflict situations at three levels, 
starting with the community and system level, moving to the school level, and finally to the classroom level, concentrating at this last level due to its importance in influencing the learning and development of both students and teachers.

\section{Teacher emotional conflict}

While the educational literature has described teachers' prior beliefs and conceptions (for example, Prawat, 1992; Hashweh, 1996), and the cognitive conflict that sometimes faces teachers during learning and professional development, there is almost no mention of the emotional conflict and anxiety that seem to accompany (or underlie) learning when teachers are involved in educational reform. Most of the six teachers mentioned their fears, hesitations, or anxieties in the cases they wrote. One of the teachers wrote almost at the beginning of her case: 'I felt afraid from the new experience about which I was to embark.' Another wrote: 'I could not reveal my fears to my students, but informed them that I was not an expert on the different facets of democracy.' One of the main reasons for the anxiety was that the teachers were not very familiar with the subject-matter that they were to teach, as the last quote reveals; only the social studies teacher felt she was well-prepared to teach democracy. The same teacher quoted above started her case by writing: 'The beginning of the Project was very difficult for me. As a teacher of physics I did not have the necessary background to teach democracy. I felt I was the least qualified person to teach this subject.'

However, others were anxious about using the new student-centered teaching methods, methods that were in contradiction with the traditional teacher-centered methods that they usually used, and that required new roles for students and teachers, and new beliefs about these roles. A third teacher wrote: 'I was highly hesitant ... I was not familiar with the new teaching methods, teaching through the use of self learning, or self-service classrooms as I like to call them, where you divide students into groups, re-divide these groups and re-group them in new groups, and additional groups until you lose your mind... I was highly skeptical about the efficiency of this method, thinking that it is not appropriate for our school students. It might be appropriate for graduate students, or maybe for special students who are serious, industrious and motivated.' He added later: 'We agreed to use the new methods to teach democracy. And I saw a similarity between using the small group approach and the teaching of democracy; both ideas were somewhat alien to our society. Learning in small groups, when the educational system has made the use of traditional teaching methods in languages, social sciences, mathematics and science scripture, will meet the same degree of surprise and estrangement as teaching about the concept and meaning of democracy, with 
its related elements such as accountability, separation of powers, and diversity, under an [Palestinian] authority that has not heard about such terms, or an [Israeli] occupation that has not the slightest regard to democracy and human rights.'

With such hesitation, skepticism, and anxiety among the teachers the question arises as to what motivated them to participate in such a Project. The main motivation seems to have come from the desire of these self-selected teachers to develop professionally. Many simply wanted to improve their practice. One teacher wrote: 'Curiosity and the desire to change my teaching style that has not changed since I became a teacher in the present school six years ago motivated me to risk joining this Project.' However, the more important motivation seems to have occurred when the teacher realized a gap between his or her existing practice and some ideals and goals that she or he held (see also Atkin, 1992; for a detailed description of teacher learning in this context see Hashweh, in preparation). Another teacher, Afaf - who had a black-belt in karate - wrote that she had successfully used coercion and intimidation to control her students, and later realized that this is not how she wanted to treat her students. She added: 'This situation began to bother, even suffocate, me.' This motivation, expressed as a desire to resolve a conflict between the actual and the ideal, set off a variety of emotions such as guilt and apprehension among some teachers. These emotions are depicted most clearly in two cases by two female teachers who co-taught a unit. One of the cases described the teacher's experience in teaching the unit, while the other described the first teacher's development as observed and perceived by the other. The two teachers confess to each other about their mutual hesitations and apprehensions at the beginning of the Project, and offer mutual support to deal with these emotions. One of them, for instance, wrote about the other: 'Afaf told me she could not sleep last night. She was particularly troubled because she believed her students did not have the abilities necessary to succeed in the required activities. 'Can they learn autonomously? Can they use the democracy concepts to understand and analyze reality, or to take positions and defend these positions? Can they debate and convince others about their views? I do not believe ninth grade students can analyze cases, pose questions, and come up with recommendations,' she asked.' We notice from the case that the other teacher's confidence helped Afaf gain confidence. Afaf also used her colleague to express her ideas and emotions, and to think aloud in order to organize her thoughts, and to reflect on these ideas and emotions, and not necessarily to seek answers from her colleague.

Afaf, as shown in her colleague's case, realized right from the beginning a discrepancy between the way she treated her students and the teaching of democracy. She expected her student to confront her with this contradiction, and indeed, she wrote in her own case that one of her students exclaimed: 'Are you 
going to teach us about democracy! You are the last person who could do that. As a teacher you only order us around. Your gaze is enough to frighten us, and no student dares to stand up to you. You are a dictatorial teacher.' This serves to heighten her sense of guilt. The other teacher wrote in her documentary case that Afaf became greatly critical of her behavior towards her students. She adds that Afaf whispered to her: "Why am I feeling that I have committed a crime? All other teachers do the same. Maybe I was a little bit stricter, but they did the same. I should take the whole thing more lightly.'

The weekly meetings that the participant teachers attended helped to provide the mutual support to face these emotions; each discovered that she is not the only one with apprehensions or problems, and that 'we're all in this together.' We often were also able to jointly discuss different solutions to the problems faced by the teachers. The professional climate that characterized these meetings, with emphasis on openness, constructive criticism, and provision of help, facilitated this process, although teachers varied in their willingness to put their thoughts, feelings, and practices on the 'examination table.' The long period of the Project also helped in building trust between the participants. This sense of trust was very important to the learning process of the teachers, since it allowed them the opportunity to express their ideas and feelings, to discuss them, and to construct or accept new ones when needed. (See also Brown, 2001, and Maria, 2000, who emphasize the importance of trust in learning in very different contexts).

This process of expressing one's ideas and feeling to others became even more difficult for some when they started writing their documentary cases. One teacher told us that writing the case made her feel like getting naked in front of others. In spite of this, this particular teacher saw great value in the discussions during the weekly meetings. When a teacher posed a problem that she faced for discussion and saw how another views it from a different perspective or a third proposes solutions that she had not thought about, this allows her to reconstruct her experience and to deepen her understanding, and, simultaneously, this allows her to realize the importance of discourse in knowledge creation, or the social construction of knowledge.

Although the initial motivation to join the Project was a desire to develop professionally, at later stages it appears that the nature of this motivation might have changed. In light of the profound difficulties that some met at the initial stages of implementation, the main motive to continue was perhaps the sense of obligation to continue or the avoidance of the embarrassment of withdrawing. One teacher wrote: 'I did not know whether there was any point to what I was doing or whether it was all in vain - periods lost with nothing achieved. I had no choice: I had started the Project, and I had to complete it.' When the same teacher achieved success at the end of the Project she was exuberant: 'Samer [one of her students 
who had initially displayed negative attitudes towards democracy and its study] has changed his mind, and this was something I had never expected. This was a great achievement for me, and I felt the delight of success.' The final motivator for all teachers was sensing indicators that their students had learned, better understood a concept, became more skillful, or developed positive attitudes toward the subject matter they were teaching. Although monitoring student involvement in classroom activities was initially used by teachers to assess their teaching effectiveness, student learning was finally the main yardstick with which they assessed their success or failure.

The cases were revealing in illuminating the emotional states, goals and motivation of the participant teachers, and they indicate that teacher learning, like student learning, is warm and whole, and quite different from the cold cognitive learning that is usually described and analyzed.

\section{Conflict at the educational system and community level}

The six teachers involved in the Project were granted permission to teach the democracy unit using class periods that were usually assigned to civic education, social studies, or library. Nevertheless, the teachers felt under enormous pressure to finish teaching the unit in the minimal amount of time in order not to affect the coverage of the curriculum they were usually teaching. Education Ministry supervisors, principals, and parents expected teachers to teach the official curriculum, and to use the textbooks authored and published by the Ministry, as in many other countries in the area, and attempts to change this status quo were sometimes perceived as subversive. Since we had secured permission from the administration of the different school systems and the principals for the Project, the teachers met few problems with the administration. However, some teachers failed to communicate well with the parents about the goals and methods of the Project, and this created some conflict situations for them.

This conflict is well documented in Afaf's case:

'One day Farah, one of my students, started crying in class. I learned, upon questioning her, that her father had found out she was studying about democracy. He wanted to forbid her from going to school, and tore up all the materials and papers she had for the Project. He said he did not send her to school to study such principles. When she argued with him he became more furious, attributing her willingness to argue with him and to disobey him to the democracy education Project. She added that her father was coming to see me and the school principal. 
The second day Farah's father came to the school, accompanied with some of the members of the executive committee of the Parent's Council [the Parent-Teacher Association]. I, and the principal, met with them. The father was very angry and spoke in an offensive and harsh manner. He accused me of inciting the girls to rebel against their parents. He explained that democracy is in contradiction with our Islamic faith, and that it helps girls stand up to their parents and to do what they wish. Finally, he added that he thinks I should concentrate on teaching the basics, language and mathematics, rather than this democracy stuff.'

The teacher continues to describe how a member of the Executive Committee, an Islamic cleric who had come to the meeting upon the father's request but who had not been previously informed about the nature of the problem, disagreed with the father, and showed how Islam is compatible with democracy and women's rights. At the end of a long meeting the father reluctantly agreed to allow his daughter to continue studying the democracy unit.

While this case describes how some parents objected to the content of the unit, other cases describe how they objected to the teaching methods used. One teacher wrote that students and parents accused him of not teaching any more: 'I heard one student say that this method of teaching is easy for teachers since we now have to do all the work while the teachers take the credit for our learning. In other schools parents complained to the administrations, and questioned the teacher's role, and even cast doubt on the teacher's competencies in some cases.'

\section{Conflict at the school level}

The conflict situations at the school level were no less serious than those at the larger context level. Afaf's case describes how she managed to convince her principal to grant her permission to teach the democracy unit without affecting the principal's sense of grandiose, after the later was offended that the teacher knew about the Project before her. The same case describes how Afaf got in trouble with her students in other classes who accused her of bias in selecting one particular section to study about democracy and neglecting other sections. She also described how she was able to change her behavior when interacting with students in the class section that studied the democracy unit but not with students in other sections, and the dilemma that she faced. Another teacher described how she was put in a conflict situation with one of her colleagues: 
'Democracy is still freedom to most of the students even after all they had studied about the principles and elements of democracy. Whenever they wanted to do whatever they liked they justified it by saying that this is democracy - being free, complete freedom with no accountability or constraints by law. This caused a big problem with the history teacher. He had planned to discuss democracy as part of the history course he was teaching. When he reached that unit they accused him of treating them in an undemocratic manner. They insisted that as part of democracy they should decide on what they should study and how to learn it. The teacher talked to me about this incident in the teachers' room, and accused me of inciting his students to rebel against him. Although he was initially harsh, he mellowed down when I told him about the Project, about the tenacious misconceptions that the students held about democracy, and about my efforts to confront these misconceptions.'

While the cases describe these external conflict situations that the teachers were put into, they also show how tactful and dedicated teachers can manage to face these situations, and reach resolutions that break down the barriers to educational innovations.

\section{Conflict at the class level}

Conflict at the class level was the most difficult for teachers and students alike, and while it was sometimes manifested as external conflict between teachers and students or amongst students, the more important kind of conflict was internal. Teaching and learning about democracy introduced internal conflict and sometimes necessitated radical changes in the thoughts and behaviors of students and teachers alike. Learning, in this context, was not solely additive and cumulative, but was occasionally characterized by qualitative changes in the learners' thoughts and behaviors. I shall start by briefly describing one conflict situation that affected student learning, and later describe situations that affected teacher learning in more detail - a more detailed description and analysis of these situations is found in Hashweh (in press).

\section{Students' conceptions about democracy}

I have chosen to describe and discuss one illustration of a conflict situation that faced students and teachers resulting from the students' prior conceptions about democracy and attitudes towards it. It is revealing that most of the six 
documentary cases show that students came to the study of democracy with alreadyheld ideas about and attitudes towards democracy. Some of these conceptions were sophisticated. In the case written by Afaf she described how her students equated democracy with freedom and freedom of choice. They were also adept at seeing the gap between the reality at home, the school, and the larger society on one hand, and how things should be in a democracy on the other hand. However, the cases also reveal that many students held inaccurate conceptions and negative attitudes. Many, for example, thought democracy means complete freedom unrestrained by law or accountability. They believed that the only restraint should be internal, that is self-control. This, of course, makes many of the elements of democracy, such as legislation, the rule of law, and accountability, unnecessary.

When the students started to discuss the teaching cases presented to them, and to read about the different element of democracy, many faced conflict between their prior inadequate conceptions of democracy, on the one hand, and reality as described in the case and the readings about democracy on the other hand. One teacher wrote her case focusing on these prior conceptions, the ensuing conflicts, and the results of these conflicts. Samer, one of her outspoken students, initially defined democracy as 'the freedom of a person to do whatever he likes within a certain framework.' When she asked him to explain what he meant by that, he answered that there are certain persons who do not know where the boundaries on their freedom lie. He made it clear that restrictions on behavior should be internal only. When discussing the political process in Palestine he saw no need for accountability: 'As long as we have chosen our authorities through elections, they are authorized after that to do what they deem appropriate, to chose the means that they find suitable.' The case that this particular class studied was about consuming expired canned food (sardines), and the health problem that this caused. Students discussed the causes of the problem, and how to solve it, discussing issues about who should be held responsible for the presence of expired food in food stores, the separation of power, the adequacy of legislations and how to influence legislation, and the rule of law. One important piece of information in the case, that some middle-level person in the Palestinian Authority might have had some connections with the distribution of expired food products, caused conflict for Samer. Towards the end of studying the unit, the teacher was surprised by the change in Samer's position:

'The most important result was that Samer discarded his belief that democracy is freedom. When we were discussing the separation [and balance] of powers Samer said: 'No authority should have absolute power.' I replied, repeating what he had said a few weeks earlier: 'As long as we have chosen our authority and government 
through elections, aren't they free to do what they like after that?' Samer answered passionately, 'No. democracy is not absolute freedom. What if these rulers abandoned the principles they were proclaiming during election? Do we leave them to play havoc with our society? Do we leave them to import expired food products for the poor people who believed in them?",

\section{Teachers' beliefs about students}

Most teachers held two prior beliefs about students, as evidenced by the cases they wrote, beliefs that they were required to reconsider when they faced cognitive conflict during the teaching of the case-based democracy unit. The first belief was that students characteristics were stable across time and domain. A 'smart' student will stay smart in the future, and if he/she is smart in languages then he/she will be smart in other subjects, such as mathematics, as well. These stable characteristics or traits might be intelligence, motivation, effort, or distinction. In one case the teacher worried that a student displayed negative attitudes towards democracy, and expected that he would not change his attitudes. In another story the teacher candidly describes her surprise when a student, who was poor in mathematics, demonstrated strengths in other areas when working in a small group:

'As I had expected, the students in each group chose one of the good students as a group coordinator except for one group, where the students chose Samar who was a very poor student in mathematics. I couldn't but express my surprise to this group asking: 'You have been chosen by the group?' I was curious, and asked each group what criteria they had used to choose the coordinator. Each group answered that they chose the student because she was a good student, except for Samar's groups. They told me that Samar was a good student in Arabic, and that she wrote short stories and poems, and that is why they had chosen her. I did not know what to answer. I had thought she doesn't understand anything. ... I kept a close eye on Samar's group to observe how she conducts herself. I wasn't sure why I did that. Was I feeling guilty about my hasty judgment and the way I had treated her in the past? Or did I want to prove to myself that I was right?'

Samar surprised the teacher again by proving to be the best coordinator in the class. In a third story a teacher described his skepticism about small group work. 
He added that he expected students "who are industrious and study under traditional teaching methods will maintain the same standards under any other teaching method'. He was surprised when he saw three 'poor' students, who hardly participated in any class activity during his Arabic periods, the stars of an after-school basketball game to which he went for the first time.

In all three cases we find that what initiated the conflict was the discrepancy the teacher discovered between his or her beliefs, or the expectations based on these beliefs, and a certain incident that occurred while teaching (a student changing his attitude towards democracy, a poor student in mathematics excelling in Arabic, inactive students in Arabic periods becoming the center of activity and attention in a basketball game). This conflict led the teachers to reconsider their initial beliefs about one-dimensional stable intelligence and to appropriate the theory of multiple intelligences that was presented to them in the workshop. In the first case, when she realizes that her student had changed his attitudes towards democracy the teacher wrote: 'I realized that making prior judgments about the outcomes of teaching is not correct.' In the second case, the teacher not only changed her beliefs about Samar's abilities, but used the theory of multiple intelligences to direct the attention of students in another small group to the talents of a girl with low status, in an effort to raise her status and, thus, to engage all students in work. The third teacher displayed an emotional reaction, in addition to the conceptual change that he underwent: 'This compelled me to reconsider my theories and repertoire of teaching methods ... If this energy is available here in the basketball court, why can't it be available in my class? God how much time I have lost in front of silent, stiff and lifeless benches. Please forgive me God.... I should avoid making prior judgments on behalf of any student. A student can be a good achiever in one area and a poor one in another, or vice versa.'

This change in teachers' beliefs about student abilities was the most profound change that occurred in their thinking, and we find evidence for its occurrence in five out of the six cases written by the teachers. Two factors facilitated this change: the anomalous events that contradicted with the teachers prior beliefs, and the presence of an alternative belief - the theory of multiple intelligences that was presented to the teachers. The importance of teachers actually engaging in practice and learning from practice has to be stressed, and in particular the dual role of anomalous events - they simultaneously contradict with prior conceptions and lend support to new ones.

The second belief about students that many teachers held was that their students have low abilities. One teacher described them as 'academically poor,' while a second described them as 'not having the intellectual skills necessary for the activities suggested by the Project.' A third claimed they were unmotivated and not serious. Since the teachers believed their students had low abilities or 
motivation to begin with, and since these 'traits' do not change with time (the first belief above), then they concluded that they will not learn anything worthwhile as a result of the project. In this case, the teachers' beliefs changed when they conflicted with reality. One teacher expressed this change best: 'The outcomes that I got with this class was different from what I had expected. I had thought that I would never succeed with this class no matter what teaching method I use. In reality, I was astounded by the results. How is it that these students who never understand what I explain in class now understand and analyze? How is it that these students, who had never heard a word of praise from me, achieve so well and disprove my hypothesis?'

\section{Teachers' beliefs about democracy and about discipline}

Some teachers shared with their students the belief that democracy means total freedom, and that only self-control should be used to regulate behavior, with no need for external constraints and mechanisms for monitoring and guiding behavior. This does not mean that the teachers did not simultaneously hold sophisticated and accurate conceptions of democracy, but these will not be discussed here. These beliefs interacted with the teachers' beliefs about classroom management and discipline, and, consequently, are described together in this section. In the first conflict situation I describe, I use the case of Afaf to show how she had to reconsider her beliefs about discipline in light of the contradiction she realized between these beliefs and her beliefs about democracy.

Afaf initially held two salient beliefs about her students and classroom discipline. She believed that student should be well disciplined in class for learning to be effective. She also believed that students do not have adequate selfcontrol to behave properly in class. She used these beliefs to rationalize her initial intimidating behavior towards her students. However, as we saw earlier, she soon realized a conflict between her practice and the implications of her new conceptions of democracy. To treat her students in a more 'democratic' manner, she had to change her initial belief about students and believe that they can exercise self-control. Examination of the two cases written by Afaf and by her colleague reveal the important role of dialogue, reflection, and deliberations in allowing Afaf to make the necessary changes in her beliefs, and, accordingly, in her practice. Afaf's colleague described how Afaf was hesitant throughout the teaching of the democracy unit to allow her students latitude in behavior or expression. Afaf was especially appalled by the criticism that her students made of the school discipline policies and practices, and the alternatives they proposed. She considered them rude. It took her colleague some effort to convince her that this was eventually in the teacher's own interest: 'Don't you see that they have 
developed a good understanding of the rights and duties of citizens? You will find it easier to deal with them in the future because they have developed and discussed rules and policies that will act as guidelines for their behavior. They have accepted them, and you will have little discipline problems in the future.' Afaf, convinced by now that the teaching of democracy would help her students exercise more selfcontrol, changed her behavior. 'I started to allow them to take part in decision making, especially in issues that were closely related to them,' she wrote. She added later, 'The relation between me and my students became a friendship relationship, and we started to deliberate and debate using our minds and logic.' However, she changed her practice only in that particular section: 'I could not interact with students in other sections in the same manner because they had not studied the principles of democracy. If I treat them in a manner similar to the one I used in this class I believe they will go overboard in their behavior because they do not know their rights and obligations, and there will be no constraints to check their behavior. My students would be committed to the school regulations because they internally believe in them and not out of fear of me or of punishment. Fear can temporarily induce discipline, but internal self-control, which results from students knowing their rights and duties, is more lasting.'

Another conflict situation occurred when some teachers, upon using small group work, found the sound level in the classroom irritating and unacceptable. Having been used to traditional teacher-directed classrooms, they expected very low noise levels. This conflict between beliefs or expectations and classroom reality again triggered thinking on the teachers' part. However, and in contrast to the last conflict situation, this conflict did not lead to a change in the teacher's beliefs or expectations. One teacher discussed this issue in her case at some length. She had problems with the high noise level, especially at the beginning of the period. However, she attributed the high noise level to the use of inappropriate furniture, heavy desks that were hard to move in order to arrange them for small group work. She wrote at the end of her case: 'All my efforts failed to change the chaos at the beginning of each class period. I realized that the real problem lay in the physical set up of the classroom, and that this should be taken into consideration to provide the necessary environment in the future.' She did not entertain the idea that a higher noise level, compared to that during traditional teaching, is acceptable, and desirable - no genuine group work can occur without dialogue. This lost opportunity for teacher development occurred because she did not have an alternative to her prior beliefs or expectations. People will not abandon an idea if they do not have an alternative one (see Hashweh, 1986; Posner, Strike, Hewson \& Gertzog,1982 for a discussion of conceptual change in science).

The third conflict situation occurred when teachers wanted their students to express and defend their ideas, and to have the courage to defend their rights as 
part of democracy education, yet often found students 'rude' when they actually engaged in such practices. The teachers set goals and expectations for student behavior when learning about democracy. However, when the students acted in accordance with these expectations teachers felt uncomfortable because these new student behaviors contradicted teachers' prior expectations about student behavior. Some of them were not able to draw a line between desirable courageous behavior and rude behavior.

This conflict is evident in Afaf's case. She wrote: 'I hated this weakness, docility, and submissiveness to orders that characterized my students... Fear controls their minds and tongues. ... How can I make these girls demand that their rights be respected?' Yet when these girls submitted a proposal that evaluated the existing school discipline policy and demanded amendments, she found them, according to her colleague, radical and rude. Another teacher punished a student when he asked about the final use of the report that his group wrote. The teacher felt that the student was rude, and did not see that the student was worried about his intellectual rights as a coauthor of the report. He could actually have used the incident to discuss intellectual property rights in a democracy rather than punish the student. Again, this is an example of a lost opportunity for teacher learning and development since this teacher did not have the chance to discuss this incident with his colleagues in spite of the design of the Project that included weekly meetings to discuss teaching and to plan for it.

Some teachers believed that democracy entailed that students be engaged in decision making regarding all aspects of teaching, including a say in the content and methods of teaching. I have already pointed out that some students shared the same belief. Some teachers experienced a conflict between this interpretation of the implications of democracy for teaching and learning, and the necessity of teaching a specific unit on democracy using a specific approach, and grouping students in heterogeneous small groups. In many cases the teachers could not resolve this conflict, and we find that they ended their cases struggling with these dilemmas.

Afaf's case describes how she faced this problem when she tried to divide her students into heterogeneous small groups. High achievers wanted to work together, and refused to have poor achievers in their groups, claiming that the latter will not work hard, and that the group's grades will consequently be lowered. She informed the students that the way she had grouped the students was final, and not open for discussion. Some students answered, 'How are we going to study about democracy while you are using your authority as a teacher to enforce decisions from the beginning of the Project?' The teacher added in her case: 'In spite of the fact that I completely agreed with what they said, I answered that this grouping was for their own interests, and I ended the discussion.' 
Again we notice that when the teacher, Afaf, did not have a chance to discuss this problem with others, that is to deliberate and reflect on her practice, and to be exposed to alternative ideas, she did not change her prior ideas, in this case her beliefs about democracy its implications for teaching. However, as we have seen earlier, the same teacher changed her ideas about student ability to self-control their behavior when she had the chance to discuss the issue with her colleague. As for Afaf's (and some other teachers') misconceptions of democracy, she assumed that democracy means providing freedom for choice for every individual in every situation that requires decision making. She was not cognizant that democracy entails freedom of choice within certain constraints. She, and other teachers, could have used such opportunities to discuss the nature of democracy in class, to provide for alternatives within constraints, and to show that the Project actually provides these alternatives. Students, for example, could choose which democracy subtopic (element of democracy, such as rule of law) they wanted to study, what problems and questions to define and pursue, how to answer these questions, and what format their final project should take. She could also have allowed students to have some choice in joining the different groups, as long as each group remained heterogeneous.

\section{Teachers' beliefs about democracy education}

Teachers held many beliefs about the aims of democracy education that I shall not try to identify here in full. I shall only emphasis the conflict that some teachers faced when they sensed the gap between the principles of democracy and the Palestinian reality. Teachers faced with such a conflict questioned the value of teaching students about democracy. The teacher who was particularly affected by this conflict was Afaf, who entitled her case 'Democracy in a Refugee Camp?' The title reflects the teacher's doubting the possibility of democratic life or democracy education in a camp. In spite of this initial hesitation, she taught the democracy unit, and was greatly surprised by the success she met. Her students became daring in asking for their rights and defending these rights, which was the most important goal of democracy education for Afaf. We have already mentioned how she found them almost rude when they daringly criticized the status quo regarding school discipline in their school, and suggested modifications in the school policy and regulations. She described incidents that also show the benefits of democracy education for her students.

In the first incident the students wanted to leave school to join in a rally against occupation on a certain day that celebrated a national occasion, but the principal refused to allow them to leave the school. The teacher intervened, and asked her students to discuss the issue with the principal. The students elected some 
representatives who negotiated a solution with the principle that allowed the students to join the rally after the fourth period that day. The class discussion after this reflected how students have internalized many of the democracy ideas discussed in class, and how empowered they felt. The episodes provides evidence that the case-based approach had succeeded in helping students acquire knowledge that they can use in their personal and social life, in contrast to the knowledge that they keep in 'cold storage' to use only in exams during traditional teaching. The second episode described how one of the students mentioned that they had stopped cheating in mathematics exams after studying the democracy unit, and did not need the teacher to proctor these exams. Afaf seems to have been greatly successful in achieving her important goal of democracy education inducing student self-control.

Afaf, due to this success she met in teaching democracy, became worried that she had provided her students with a disservice; she believed that her students who were all female, now adamant about protecting their rights, would be faced with problems in the future in a male-controlled and undemocratic society. In reality, these questions reflect Afaf's views of the aims of education in general: to prepare the individual to adapt to society and maintain the status quo or to change and transform her or his society? Due to her adherence to the first aim she faced a conflict, a dilemma that remained unresolved.

\section{Conclusion}

This last incident about Afaf worrying about the future of her students ironically reveals that after three years of participation in the Project, and in spite of the sometimes drastic changes that occurred in her thinking and practice, she has still not realized an important aspect of the Project - mainly, that teachers should and can participate in the struggle in their society to change the status quo. As mentioned in the beginning of this paper, many Arab intellectuals and educators (e.g., Barakat, 1984; Sharabi, 1975, 1987; Watfa, 1996, 1999) have criticized Arab culture and society as patriarchal and authoritarian, and have identified cultural values, home child-rearing and school practices that are barriers to democracy in the Arab World, but have not clearly explained how changing this state of affairs should occur. The main premise of the Project, still not completely realized by the teacher Afaf, is that schools, like other social organizations, are arenas for the struggle between conservative and progressive movements in the society.

Students and teachers have approached democracy education with prior ideas, experiences, and expectations that sometimes stood in contradiction with the ideas concerning democracy and pedagogy that they were exposed to. This had 
occasionally triggered cognitive and emotional conflict, and prompted them to undergo examination and reorganization of their mental structure. When teachers faced conflict, and were able to reflect on their prior ideas and to entertain new ideas with the support of their colleagues and Project leader, they underwent important qualitative changes in their ideas and practices, and, therefore, developed professionally. On other occasions, the teachers did not have the chance to think through these conflicts or to consider new alternative ideas, and the conflict did not lead to radical change.

In this article I have emphasized the emotional and cognitive conflicts that the students and teachers faced when learning and teaching about democracy. The cases, however, also replicate the findings of previous studies about the relations between culture, society and schools in the Arab States. In agreement with AlNaqib (1993) and Watfa (1996, 1999) we found that students and teachers sometimes initially held beliefs about student-teacher interaction and appropriate classroom behavior, and about democracy that reflected an authoritarian culture. Teachers like Afaf continued to struggle with the implications of democracy for student-teacher interactions until the end of her case, and still was uncomfortable with student honest expression of their ideas because she did not completely give up her old emphasis on obedience. She has still not finally resolved the differences between rudeness and civility. It is precisely because the Project necessitated the introduction of new content, pedagogy, and student-teacher relations that were in dissonance with prior practices and beliefs that conflict was created. In contrast to previous studies that emphasized how schools reflect and maintain the culture and the social structure, the cases show how students and teachers were able to undergo important changes in their ideas and behavior. The cases describe classes that did not reflect authoritarian values, but exemplified democratic relations, and were enhancing the process of democratization in Palestinian society.

We have found that teaching democracy occasionally creates conflict. If we view democracy as a tool for struggle, a means of changing reality through resistance and dialogue, then the contradiction between learning and practicing democracy disappears - in either, conflict is a major component of the process. Struggle for democracy, justice and freedom is necessarily characterized by conflict. The importance of the teacher written cases in this Project lies in revealing the deep, rather than the surface, aspects of this conflict - the internal emotional and cognitive conflict that accompanies external visible conflict. Their strength also lies in bringing to our attention that changing reality dialectically interacts with personal change. Additionally, the use of teacher-written cases has allowed teachers to tell their own stories, to sketch their own accounts of their attempts at educational innovation and change. These stories show that while teaching democracy in Palestine is a very difficult process, it can be successfully 
undertaken. They are stories of courageous and dedicated teachers who tactfully surmounted the obstacles to teaching democracy in an essentially undemocratic context. It may be striking that all six cases turned out to be mainly stories about conflict and struggle. But should we have expected that stories about attempts to change the status quo, even the educational one, in a context of a society struggling to achieve statehood, to build its own civil society and democratic institutions, and to achieve independence from a foreign military occupation to be any different?

\section{Notes}

This work was made possible in part by the opportunity to dedicate my time to writing afforded to me as a Visiting Scholar at the Carnegie Foundation for the Advancement of Teaching and at Stanford School of Education during the academic year 2001/2002. It was also made possible by the funding and support by Carnegie Foundation during this year, and that to a three-year Project by Almawrid and Muwatin institutes in Ramallah, Palestine, and by Ford and BILANCE foundations.

Maher Z. Hashweh is Associate Professor in the Department of Education at Birzeit University, Birzeit, Palestine. Contact Address: P.O. Box 38518, East Jerusalem, Via Israel.Telephone and Facsimile: +972-2-2406401; e-mail: mhashweh@birzeit.edu

\section{References}

Al-Naqib, K.H. (1993) 'The educational dilemma and the silent revolution: a study in the sociology of culture.' Al-Mustaqbal Al-'Arabi, 16(174), 61-74. [in Arabic]

Atkin, J. M. (1992) 'Teaching as research: an essay.' Teaching and Teacher Education, 8(4), 381-390.

Bahlool, R. (1997) Education and Democracy. Ramallah: Muwatin.

Barakat, H. (1984) Contemporary Arab Society. Beirut: Center for the Study of Arab Unity. [in Arabic]

Bowles, S. \& Gintis, H. (1976) Schooling in Capitalist America: Educational Reform and the Contradictions of Economic Life. New York: Basic Books.

Brown, J.S. (2001). 'Storytelling: scientist's perspective.' Paper presented at the weekend symposium at the Smithsonian Associates on Storytelling: Passport to the $21^{\text {st }}$ Century, Washington, DC. (April 20-21).

Durkheim, E. (1956). Education and Sociology. Glencoe, Ill.: Free Press.

Fagerlind, I. \& Saha, L. (1989) Education and National Development: A Comparative Perspective. New York: Pergamon. 
Haidar, A.L. (1996) 'Patriarchal relations and their effects on scientific attitudes of secondary school students in Yemen.' Al-Mustaqbal Al-'Arabi, 19(214), 86-106. [in Arabic]

Hashweh, M. Z. (1986) 'Toward an explanation of conceptual change.' European Journal of Science Education, 8(3), 229-249.

Hashweh, M.Z. (1996) 'Palestinian science teachers' epistemological beliefs: a preliminary report.' Research in Science Education, 26(1), 89-102.

Hashweh, M.Z. (in press) Democracy Education: A Case-Based Approach. Ramallah, (Palestine): Muwatin \& Almawrid. [in Arabic]

Hashweh, M. Z. (in preparation) 'Teacher accommodative change.'

Hashweh, M. Z. \& Njoum, I. (2001) 'A case-based approach to education in Palestine.' In R.G. Sultana (ed.) Challenge and Change in Euro-Mediterranean Region: Case Studies in Educational Innovation. New York: Peter Lang.

Maria, K. (2000) 'Conceptual change instruction: a social constructivist perspective.' Reading \& Writing Quarterly, 16(1), 5-22.

Posner, G.J., Strike, K.A., Hewson, P.W. \& Gertzog, W.A. (1982) 'Accommodation of a scientific conception: toward a theory of conceptual change.' Science Education, 66(2), 211-227.

Prawat, R.S. (1992) 'Teachers' beliefs about teaching and learning: a constructivist perspective.' American Journal of Education, 100(3), 354-395.

Sharabi, H. (1975) An Introduction to the Study of Arab Society. Jerusalem: Salah Eddin Publications. [in Arabic]

Sharabi, H. (1987) The Patriarchal Structure: A study of Contemporary Arab Society. Beirut: Dar Al-Tali'a. [in Arabic]

Watfa, A. (1996) 'The social backgrounds of educational interactions in Arab universities: the University of Damascus as an exemplar.' Al-Mustaqbal Al-'Arabi, 19(214), 74-85.

Watfa, A. (1999) 'Manifestations of authoritarianism in contemporary Arab culture and education.' Al-Mustaqbal Al-'Arabi, 22(247), 54-71. [in Arabic] 